\title{
Investors' attention: does it impact the Nigerian stock market activities?
}

The Nigerian stock market activities

\author{
Osarumwense Osabuohien-Irabor \\ Department of International Economics, School of Economics and Management, \\ Ural Federal University Named After the First President of Russia B N Yeltsin, \\ Ekaterinburg, Russia and \\ Department of Statistics, Ambrose Alli University, Ekpoma, Nigeria
}

Received 28 February 2020

Revised 17 April 2020 1 June 2020

Accepted 4 June 2020

\begin{abstract}
Purpose - The author investigates whether investors' online information demand measured by Google search query and the changes in the numbers of Wikipedia page view can explain and predict stock return, trading volume and volatility dynamics of companies listed on the Nigerian Stock Exchange.

Design/methodology/approach - The multiple regression model which encompasses both the univariate and multivariate regression framework was employed as the research methodology. As part of our preanalysis, we test for multicollinearity and applied the $\mathrm{Wu} /$ Hausman specification test to detect whether endogeneity exist in the regression model.

Findings - We provide novel and robust evidence that Google searches neither explain the contemporaneous nor predict stock return, trading volume and volatility dynamics. Similarly, results also indicate that trading volume and volatility dynamics have no relationship with changes in the numbers of Wikipedia pages view related to stock activities.

Originality/value - This study opens new strand of empirical literature of "investors' attention" in the context of African stock markets as empirical evidence. No evidence from previous studies on investors' attention exist, whether in Google search query or Wikipedia page view, with respect to African stock markets, particularly the Nigerian stock market. This study seeks to bridge these knowledge gaps by examining these relations.

Keywords Google search, Wikipedia page view, Investors' attention, Information demand, Volatility, Stock returns

Paper type Research paper
\end{abstract}

\section{Introduction}

Attention is a key aspect of our visual experience closely relates to perception (Zagoruyko and Komodakis, 2019). And as humans, we need to pay attention in order to adequately perceive our surroundings. Attention is crucial but difficult to measure directly, hence previous studies could not provide direct measurement. For example; Takeda and Yamazaki (2006), Kim and Meschke (2011) used the appearances on TV programs as a proxy for investors' attention. The paper by Antweiler and Frank (2004) reports that Internet stock messages posted on Yahoo! Finance and raging bull can help predict stock market volatility,

\section{JEL Classification - C22, C52, G12}

(C) Osarumwense Osabuohien-Irabor. Published in Journal of Economics and Development. Published by Emerald Publishing Limited. This article is published under the Creative Commons Attribution (CC BY 4.0) license. Anyone may reproduce, distribute, translate and create derivative works of this article (for both commercial and non-commercial purposes), subject to full attribution to the original publication and authors. The full terms of this license may be seen at http://creativecommons.org/licences/by/4.0/ legalcode

The author sincerely thanks the editor and the anonymous reviewer(s) for their very helpful comments and insightful suggestions. For any other error(s), the usual disclaimer applies.

Conflicts of interest: The author declares that to the best of the knowledge, there is no conflict of interest.

Funding: The author received no funding for this research.

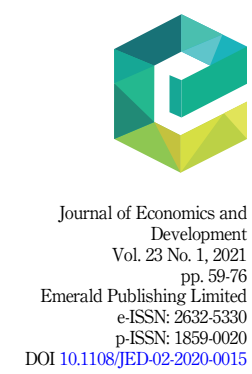


JED

23,1

60

and they found that posted stock messages impact stock returns significantly. Fehle et al. (2005) used product marketing advertisements as a surrogate for investors' attention. Their results suggest that firms that spend more on advertising, attracts a larger number of both individual and institutional investors. Fang and Peress (2009) examined the relationship between media coverage (e.g. newspaper) and the stock returns. Their analysis shows that those with high media coverage have higher returns. But what is the guarantee that these investors pay attention to such advertisements and news media? This is one of the limitation studies using the traditional indirect measure for attention suffers, hence, the need for a more direct proxy to measure investors' attention.

The popularity of Google searches among Internet users to collect information is one of the major reasons Google aggregate search frequency is use as a direct measure of attention. And as of 2019, Google receives 75,000 searches per second on any given day and 2 trillion searches per year [1]. This makes Google searches a direct proxy for attention much more valued than the earlier indirect measures. Hence, volumes of research literatures using Google searches, particularly studies related to financial markets have continue to increase. Since becoming public in 2006, Google Trends (GT) service has allowed users to see and use the aggregate search volume for any defined term or topic. Google search volume (GSV) can be used to examine the relationship between investors' attention and the financial market, particularly the stock market activities. Search word(s) undoubtedly shows attention, and the aggregate of search frequency is a direct measure of active attention (Da et al., 2011). In other words, quest for information demand on a specific topic implies investors' attention and time. Since the emergence of the famous seminal paper of Da et al. (2011), large volumes of empirical literature on Google search intensity as a measure of attention demands have been spotted in many branches of knowledge. However, despite the wide usage and popularity of Google search query in relation to stock market activities, no previous study exists with evidence from African stock markets. And to the best of our knowledge, most of the existing literature primarily focused on evidence from the emerged markets and developed economies. This contrasts with the dearth of literatures with evidence from African stock markets.

Based on empirical evidence, we categorize studies of investors' attention and stock market activities in two strands - the US stock market related studies and the non-US stock market related studies. Dimpfl and Jank (2016) investigate the dynamics of Dow Jones Industrial Average volatility and retail investors' attention. Their empirical results show that there exist a strong co-movement between the realized volatility and investors' attention. Huang et al. (2019) study indicates that the directional movement of S\&P 500 stock index due to changes in search volume is dependent on the specific term being searched for and the sentiment itself. Their study also validates GT as a measure of investors' attention. Using eighteen (18) different US companies from New York Stock Exchange (NYSE), Nasdaq Stock Market and the Dow Jones Industrial Average Index, Audrino et al. (2019) show that investors' attention and sentiment variables improve volatility forecasts significantly. Besides, their results also identify the investors' attention variables as the most relevant measure of active attention in stock market. Da et al. (2011) explore the US Russel 3,000 data, and their results shows that increase in Google searches predict a higher stock price.

Compare to avalanche of empirical evidence from US studies, not many studies have examined the relationship between investors' search intensity and stock market activities for non-US stock markets. Dimpfl and Kleiman (2019) empirical studies investigate the relationship between online search intensity and the German stock market. Their results show that an increase in retail investors' pessimism leads to an increase in volatility and trading volume but a decrease in stock return. Kim et al. (2019), examine the relationship between Norwegian stock market and GSV. Their results show no relationship between investors' attention and stock returns. The study by Aouadi et al. (2013) reveals that the investors' attention is a significant determinant of French stock market illiquidity and 
volatility, which is strongly correlated with trading volume. The papers by Takeda and Wakao (2014) and Adachi et al. (2017) also investigate the Japanese stock market. Whilst the former empirical results show online search intensity is weakly related to stock returns but strongly related to trading volume, the latter results indicate that the search intensity is positively related stock returns and liquidity. However, evidence from the Chinese stock market using Google search query as proxy for attention is quite lows. This is because most Chinese academia and investors prefer the use the Baidu index as attention proxy. That notwithstanding, Zhang et al. (2018) examined the impact of firms' sustainability on stock return and volatility. They find evidence that firms' sustainability news decreases volatility persistence and an increase in Google search engine.

Records of data from the history of viewership of Wikipedia pages (hereafter referred to as, Wiki) is another source of information demand use as proxy to measure investors' attention. Studies on the relationship between the numbers of Wiki page views and stock markets activities have not attracted much attention like the Google search query. Moat et al. (2013) seminal paper first commenced investigation to check if changes in financially related Wiki page views impact the stock market before trading decisions are taken. Their results suggest that changes in Wiki provide information for investors to make decision before stock trading. Herve et al. (2019) used the Google search query and Wiki page views' traffic respectively as a proxy for noisy traders and smart investors' attentions to investigate the stock market activities. Their study indicates that only noise traders' attention impacts stock returns and increases volatility. However, activities of smart investors' attention show to decrease volatility. Cergol and Omladic (2015) employed the Google search query and Wiki page views to investigate substantial sample of firms listed on S\&P 500 index. The Wiki records showed an inverse pattern of merry frown for the bear market and sour smile for the bull market in stock prices. The paper by Yoshida et al. (2015) indicates that frequently searched keywords are highly correlated with changes in the numbers of Wiki page views. Their results suggest that the numbers of Wiki page views can be used as an effective tool to determine popular web search trends.

But do investors search intensity using Google search query and Wiki page views impact the Nigerian stock market? Does the dearth of research literature on investors' attention and stock market activities in African stock markets connotes absence of interrelationship? These are some major question among Nigerian stock market investors, stockbrokers, policy makers and researchers interested in the Nigerian stock market. The Nigerian stock market was established in 1961 as the Lagos Stock Exchange and later renamed in 1977 as the Nigerian Stock Exchange with 19 securities listed for trading. As at November 2019 the Nigerian Stock Exchange has a total of number of 161 listed companies; 8 domestic companies on premium board, 144 companies on main board and 9 companies on alternative securities market board and a total market capitalization of over 28 trillion as at January 9, 2019. Nigeria remains Africa most populous country with a GDP of $\$ 376.284$ billion in 2017(IMF) and the largest economy in Africa [2]. And as at July 2019, Nigeria's Internet penetration reached 61.4 percent with 122 million active users which accounts for 23 percent of Internet users in Africa [3, 4]. The Nigerian stock market investors are made up of both the domestic investors and foreign investors, with the domestic investors sub divided into retail and institutional investors. With these characteristics, coupled with being the market that powers the growth of the largest economy in Africa, Nigerian stock market is an ideal context to apply and test the effects of online search intensity using GSV and Wiki as proxy for investors' attention.

This paper pioneers a new strand of literatures on the relations between investors' attention and the stock market activities in Africa context. Specifically, we examine whether GSV and changes in the numbers of Wiki page views can explain and/or predict the stock returns, volatility and trading volume in the Nigerian stock market. We find that Google searches neither correlate with contemporaneous nor predict stock return, trading volume and volatility dynamics. And changes in the numbers of Wiki page view records does not

The Nigerian stock market activities 
JED

23,1

62

influence the trading volume and volatility dynamics of the Nigerian stock market. However, our results indicate that changes in the numbers of Wiki page view related to stock negatively explain the variations in the stock returns.

The study consists of six sections, and the rest is organized as follows. Sections 2 and 3 explain our data and methodology, respectively, and Section 4 discusses the empirical results and robustness of our methodology. The concluding remarks are provided in Section 5.

\section{Data}

\subsection{Google search volume}

This study examines the GSV as a direct proxy for investors' attention to examine the Nigerian stock market trading activities such as stock returns, volumes and volatilities using the NGSE-30 index. The normalized weekly values of GSV from numbers of keywords from August 3, 2015 to August 2, 2019 are obtain, through GT. Normalization removes possible effect of the overall increase in the number of searches. Google search values range from 0 to 100. Whilst the value 0 means that the search volume is too low to provide meaningful statistics and does not literarily indicates no search, the value 100 represents the highest level of search activity during the sample specified period. GT calculates the GSV from a random subset of data. Thus, same data downloaded at different times, have slightly different results. To avoid this problem, we follow the paper by Da et al. (2011), by downloading all the GSV index data once and no data change thereafter. Downloading GSVs values several times, results in most correlations to exceed the value of $97 \%$. We focus on firms listed on the NGSE30 index on the floor of the Nigerian Stock Exchange as at June 2019. GT reports data from Sunday to Saturday. The raw downloaded GSV cannot be applied directly in analysis, because its value depends on the time period of downloaded data, hence, the need for standardization of GSV data relative to its past history.

\subsection{Abnormal GSV}

This study follows the standardization formula by Bijl et al. (2016) and Kim et al. (2019), where the average of the past 52 weeks is subtracted from the weekly raw GSV and dividing their difference with the standard deviation of the previous year. Then we compute the abnormal GSV (hereafter referred to as AGSV).

$$
\operatorname{AGSV}_{t}=\frac{X_{t}-\frac{\sum_{i=1}^{n} X_{i}}{n}}{\sigma_{X}}
$$

where; $X_{t}$ represents search volume of company $i$ in week $t$;

Note: The Wiki data are downloaded from the English language Wiki web, launched on the 15th of January 2001 and available on https:/en.wikipedia.org. The data are converted to weekly data and transformed using Eqn (1) framework. Firm's Wiki page views can be downloaded daily (both in weekdays and weekend) and months.

\subsection{Selection of keywords}

Previous papers, such as Da et al. (2011), etc., employed the ticker symbols of stocks instead of the firm name, based on the following reasons. First, user searching for firm's name may seek irrelevant information to stock investments purposes. Second, a company search name might be ambiguous with several meanings (e.g. "Apple”). Third, GT input does not allow searches for alpha-arithmetic term. Hence, company's names such as 3M, 3com, etc. cannot be search for. Conversely, several literature studies, such as; Kim et al. (2019), Bijl et al. (2016), Aouadi et al. (2013) and Bank et al. (2011); have shown preference to the use of firm's name than tickers 
names. This is because, firm's name searches have a stronger relationship to stock market returns than ticker searches. But sometimes, firms name might not return any raw data due to insufficient GSV but have sufficient GSV for firm's tickers.

To this end, this study uses aggregates GSV from both the firm's names and its associated tickers names. First, we search for the individual firm's names to get the GSV. And if the use of firm's name does not return GSV, then we search using the tickers names. And if ticker searches also fail to return any aggregate GSV, such firms are deleted. However, problems identify by Da et al. (2011) particularly the creation of random noise arising from the use of firms name not relevant to investments purposes, are address with the following procedure;

(1) We exclude terms that identify a firm's legal status, (e.g. "Holdings", "Group", "LLP”, "INC", "limited", "LTD", "international”, etc.) from the firm's name, unless excluding these terms make the company name too general

(2) We check and compare firms name as well as their associated ticker, stated in Wikipedia pages (https://en.wikipedia.org).

(3) We exclude firm's names and tickers that are found to be ambiguous or associated with searches other than firm's financial information.

(4) Previous research by Preis et al. (2013), indicates that data filtered according to geographic location or proximity can better explain movements in the specific geographic location. Hence, GT default filter is set to "All Categories" of "web search" conducted in Nigeria (locations) for the period of four (4) years, between August 3, 2015 and August 2, 2019.

\subsection{Sample selections and elimination}

This section reports sample selection and elimination of data used in this paper. The entire sample consist of 30 stocks trading firms on NGSE-30 index. Firm's trading stock data as well as their associated Wiki page views data are obtained, with procedures outline in Section 2.3 as precept. However, firm's corresponding tickers searches listed in Appendix 1 Table A1, Panel A and B, either returned insufficient GSV or have ambiguous keywords. Hence, our study used the firm's GSV data. After the selection and elimination process, a total number of twenty-four (24) firms are finally applied in our analysis. Table A1, panel B, shown the complete list of companies with no Wiki or Google search data. Thus, these companies were excluded in our final sample selection.

\subsection{Stock data}

We downloaded a total of 24,624 daily adjusted closed prices data. And used the weekly (week ending Friday) historical closing stock prices data between August 3, 2015 and August 2, 2019 obtained from the Nigerian Stock Exchange, Lagos. The NSE-30 index is a modified market capitalization index with a fixed number of thirty (30) included stocks. All firms listed on NGSE-30 as at June 1, 2019 were searched for data analysis, but firms which did not meet Section 3.3 and 3.4 selection criterion are expunge from our sample. Besides, missing data due to holidays and non-trading days are replaced by simply using the mean imputation procedures (Batista and Monard, 2003). The weekly return is calculated from the adjusted closing prices as;

$$
R_{t}=\log \left(\frac{P_{t}}{P_{t-1}}\right)
$$

where; $R_{t}$ is the raw $\log$ return, $P_{t}$ is the adjusted stock price for week $t, P_{t-1}$ is the adjusted stock price from the previous week.
The Nigerian stock market activities 
JED

23,1

64

\subsection{Abnormal return}

Following capital asset pricing model (CAPM) criticisms of unrealistic assumptions and the non-changing time frame of investment appraisals, Fama and French (1993) developed the 3factor asset pricing model which covers some of the deficiency of CAPM. Again, Fama and French (2015) developed additional 2-factors (the profitability and investment factors), which bring the total factors to 5 -factors. We calculate our abnormal returns as values obtain from the subtraction of stock benchmark (expected) from the actual stock returns shown in Eqn (2). In this paper, the Fama and French (2015) model shown in Eqn (3) generates our returns benchmark. And the daily values of the abnormal returns are converted to weekly data by compounding the returns from Monday to Monday as shown in Eqn (4), thus;

$$
\begin{aligned}
\mathrm{ARet}^{\mathrm{FF} 5}= & R_{t}-\left(R_{f, t}+\widehat{\boldsymbol{\beta}}_{1}^{\mathrm{FF} 5}\left(R_{m, t}-R_{f, t}\right)+\widehat{\beta}_{2}^{\mathrm{FF} 5} \mathrm{SMB}+\widehat{\beta}_{3}{ }^{\mathrm{FF} 5} \mathrm{HML}_{t}+\widehat{\beta}_{4}^{\mathrm{FF} 5} \mathrm{RMW}_{t}\right. \\
& \left.+\widehat{\beta}_{5}^{\mathrm{FF} 5} \mathrm{CMA}_{t}\right)
\end{aligned}
$$

where;

$R_{t}$ is the total return of stock $t, R_{m, t}$ is the market return at time $t$,

$R_{f, t}$ is the risk-free rate at time $t, R_{m, t}-R_{f, t}$ is the risk premium at time $t$,

$\mathrm{SMB}_{t}$ is the difference between small and big stock returns based on market capitalization;

HML is the difference between high and low book-to-market stock;

$\mathrm{RMW}_{t}$ is the profitability factor; CMA is the investment factor

$\beta_{1,2,3,4,5}$ are the estimated coefficients.

$$
\operatorname{Return}_{i, w}=\left(1+r_{1}\right)\left(1+r_{2}\right), \ldots,\left(1+r_{n}\right)-1=\prod_{i=1}^{n}\left(1+\operatorname{return}_{i, d}\right)-1
$$

where;

return $_{i, d}$ is the stock $i$ 's return in day $d$ of week $w$.

\subsection{Abnormal trading volume}

In the spirit of Chesney et al. (2015), we describe the abnormal trading volume as an unusual trade in option contracts which brings about large gains, usually made few days before the occurrence of a major event. Thus, to examine the relationship between the ATVol and the AGSV, the values of the daily trading volume are first converted to the weekly trading volume $\mathrm{TVol}_{t}$. Thus;

$$
\mathrm{TVol}_{t}=\frac{1}{\left|S_{t}\right|} \sum_{i \in S_{t}}^{n} \mathrm{TVol}_{t}^{D}
$$

where; $\left|S_{t}\right|$ is the numbers of trading days in each week. Thus; the values of the total volume $\mathrm{TVOl}_{t}$ are standardized as shown in Eqn (1)

\subsection{Volatility}

Financial market volatility as well as stock returns are variables of significant interest to the economists, investors and other market participants (Chung and Chuwonganant, 2018). This is because it measures the levels of risk associated with investments. For this reason, we include volatility as one of the control variables in our regression models that explains the stock returns and the trading volume. We apply the Parkinson (1980) range-based volatility estimator, which uses the high $\left(\right.$ high $\left._{t}\right)$ and low $\left(\operatorname{low}_{t}\right)$ values of daily prices to estimate the variance, see Eqn (6). Monte Carlo simulation and empirical data results by Brandt and Kinlay (2005), document that the Parkinson (1980) volatility estimator is highly more superior 
to the Garman and Klass (1980); Rogers and Satchell (1991); Alizahdeh et al. (2002) and Yang and Zhang (2000) when empirical data derived from the S\&P 500 Index were used. We calculate the variance thus;

$$
\widehat{\sigma}_{p, t}^{2}=\frac{1}{4 n \ln 2} \sum_{i=1}^{n}\left(u_{i}-d_{i}\right)^{2}
$$

where;

$C_{t}=$ Closing price on day $t ; O_{t}=$ Opening price on day $t$;

$H_{t}=$ High price on day $t ; L_{t}=$ Low price on day $t$;

$c_{t}=\ln C_{t}-\ln O_{t}$, the normalized close price;

$o_{t}=\ln O_{t}-\ln C_{t-1}$, the normalized open price;

$u_{t}=\ln H_{t}-\ln O_{t}$, the normalized high price;

$d_{t}=\ln L_{t}-\ln O_{t}$, the normalized low price;

$n=$ number of daily periods.

The weekly volatility as a square root of average daily variance is calculated thus;

$$
\text { Volatility }=\sqrt{\sum_{i \in S_{t}} \text { variance }_{t}}
$$

\subsection{Summary statistics}

Table 1 presents present two parts; the panel A which is the summary statistics and Panel B which contains correlation analysis of ARet; AGSV; AWiki, ATVol and Volatility of the NGSE-30 index between August 3, 2015 and August 2, 2019. Panel A shows the descriptive statistics of the study variables. The values of St. Dev. and mean for AGSV and Awiki appears to follow the normal distribution. Volatility is shown to be low, indicating that the historical stock prices are low with less investment risk. While ARET and Volatility have lighter tails than the normal distribution, AGSV, AWiki and ATVOL excess kurtosis appears to show sign of heaviness at the tail than the normal distribution. Almost all the variables except volatility are skewed to the left. The AGSV, AWiki and trading Volume are calculated using the Bijl et al. (2016) formula. Whilst volatility is calculated using Parkinson (1980) range-based volatility estimator, stock return is calculated from the 5-factors asset pricing model. The upper right triangular matrix side of panel $\mathrm{B}$ report the correlation matrix

\begin{tabular}{|c|c|c|c|c|c|c|c|}
\hline \multicolumn{2}{|c|}{ Panel A: Summary statistics } & Mean & St. Dev & Kurtosis (excess) & Skewness & Min & Max \\
\hline AGSV & 209 & 0.000 & 1.000 & 2.516 & 1.230 & -2.107 & 4.155 \\
\hline AWiki & 209 & -0.354 & 1.000 & 0.956 & 0.855 & -2.498 & 3.115 \\
\hline ARET & 244 & -0.016 & 0.023 & -0.112 & 0.608 & -0.066 & 0.048 \\
\hline ATVOL & 293 & -0.237 & 0.995 & 5.206 & 1.829 & -1.628 & 5.111 \\
\hline Volatility & 293 & 0.013 & 0.003 & -0.317 & -0.015 & 0.002 & 0.022 \\
\hline
\end{tabular}
analysis of our data. Our data shows low correlation values of both negative and positive.

Panel B: correlation matrix analysis

\begin{tabular}{lcrrrr} 
Correlation & AGSV & AWiki & ARET & ATVOL & Volatility \\
\hline AGSV & 1.000 & -0.329 & 0.162 & -0.014 & 0.00002 \\
AWiki & -0.329 & 1.000 & -0.098 & 0.150 & -0.005 \\
ARET & 0.162 & -0.098 & 1.000 & -0.079 & -0.480 \\
ATVOL & -0.014 & 0.150 & -0.079 & 1.000 & 0.122 \\
Volatility & 0.00002 & -0.005 & -0.480 & 0.122 & 1.000
\end{tabular}

The Nigerian stock market activities 
JED

23,1

66

\section{Methodology}

Our methodological framework is the multiple regression analysis. Our results also reject the null hypothesis of the existence of a unit root in our variables when we employed the augmented Dickey-Fuller (ADF) test with deterministic constant. This justifies our model estimations in OLS regressions. Our pre-analysis result also reveals the absence of multicollinearity as shown in Table 1 panel $\mathrm{B}$. In addition, we conduct the $\mathrm{Wu} /$ Hausman specification test for endogeneity which reject the null hypothesis that our endogenous variables are actually exogenous variable (for brevity, table not shown). We use the multivariate regression in Eqns (8)-(10) to study the relationship between investors' attention and the stock market activities for NGSE-30 index. The AGSV and AWiki are proxies for investors' attention, while the stock return, trading volume and volatility are use as the dependent variables as well as control variables alternating in the model. We regress ARet, ATVol and Volatility against the AGSV and AWiki plus the control variables in order to control the market effect. The lag variables of the dependent variables are included in our model in order to control the autoregressive pattern.

Our regression models are expressed in both contemporary explanatory and the predictive models. In Eqns (8) and ( $\left.8^{\prime}\right)$, we examine whether the current and lagged values of AGSV and AWiki explains and predict the future of NGSE-30 ARet, respectively. While the former equation investigates the contemporary descriptive relationship between stock ARet and investors' attention, the later examines the predictive relationship between stock ARet and investors' search query. The first lagged value of ARet controls the autoregressive in both models.

$$
\operatorname{ARet}_{i, t}=\alpha_{i}+\beta_{1} \operatorname{ARet}_{t-1, i}+\beta_{2} \mathrm{AGSV}_{t, i}+\beta_{3} \mathrm{AWiki}_{t, i}+\beta_{4} \text { Volatility }_{t, i}+\beta_{5} \mathrm{ATVol}_{t, i}+\varepsilon_{t, i}
$$

$$
\begin{aligned}
\operatorname{ARet}_{i, t}= & \alpha_{i}+\beta_{1} \operatorname{ARet}_{t-1, i}+\beta_{2} \mathrm{AGSV}_{t-1, i}+\beta_{3} \mathrm{AWiki}_{t-1, i}+\beta_{4} \text { Volatility }_{t-1, i}+\beta_{5} \mathrm{ATVol}_{t-1, i} \\
& +\varepsilon_{t, i}
\end{aligned}
$$

where; ARet, AGSV, AWiki, ATVol, Volatility, $\beta_{i}$ are the abnormal return, abnormal GSV, Wikipedia page views, trading volume, volatility and the regression coefficients, respectively.

Similarly, the trading volume is regressed on of AGSV and AWiki and the control variables (returns and volatility). The estimation results from Eqn (9) and (9') examines if there is the existence of a relationship between the trading volume and the investors' attention. In other word, it examines whether the lagged values of the independent variables can predict the future values of trading volume, or whether the investors' search intensity can explain the variations associated with the trading volume. The first lagged of the trading volume is added to the explanatory and predictive models to control the autoregressive effects.

$$
A \operatorname{TVol}_{i, t}=\alpha_{i}+\beta_{1} \mathrm{ATVol}_{t-1, i}+\beta_{2} \mathrm{AGSV}_{t, i}+\beta_{3} \mathrm{AWiki}_{t, i}+\beta_{4} \operatorname{Volatility~}_{t, i}+\beta_{5} \mathrm{ARet}_{t, i}+\varepsilon_{t, i}
$$

$$
\begin{aligned}
\operatorname{ATVol}_{i, t}= & \alpha_{i}+\beta_{1} \mathrm{ATVol}_{t-1, i}+\beta_{2} \mathrm{AGSV}_{t-1, i}+\beta_{3} \mathrm{AWiki}_{t-1, i}+\beta_{4} \text { Volatility }_{t-1, i} \\
& +\beta_{5} \operatorname{ARet}_{t-1, i}+\varepsilon_{t, i}
\end{aligned}
$$

where ATVol, ARet, AGSV, AWiki, Volatility, $\beta_{i}$ are the trading volume, abnormal return, abnormal GSV, Wikipedia page views, volatility and the regression coefficients, respectively. 
Eqns (10) and $\left(10^{\prime}\right)$ investigate whether there is a contemporary and predictive relationship between AGSV and Wiki on one hand and volatility on the other hand. We regressed volatility on its lagged value including the lagged values of the control variables as shown in Eqn $\left(10^{\prime}\right)$. Thus;

$$
\begin{aligned}
\text { Volatility }_{i, t}= & \alpha_{i}+\beta_{1} \text { Volatility }_{t-1, i}+\beta_{2} \mathrm{AGSV}_{t, i}+\beta_{3} \mathrm{AWiki}_{t, i}+\beta_{4} \mathrm{ATVol}_{t, i}+\beta_{5} \mathrm{ARet}_{t, i} \\
& +\varepsilon_{t, i} \\
\text { Volatility }_{i, t}= & \alpha_{i}+\beta_{1} \text { Volatility }_{t-1, i}+\beta_{2} \mathrm{AGSV}_{t-1, i}+\beta_{3} \mathrm{AWiki}_{t-1, i}+\beta_{3} \mathrm{ATVol}_{t-1, i} \\
& +\beta_{4} \operatorname{ARet}_{t-1, i}+\varepsilon_{t, i}
\end{aligned}
$$

where; Volatility; ATVol; ARet; AGSV; AWiki, $\beta_{i}$ are volatility, trading volume, abnormal return, abnormal GSV, Wikipedia page views and the regression coefficients respectively.

\section{Results of empirical analysis}

The major objective of this study is to investigate the impact of investors' online information query on large firms listed on the Nigerian stock exchange. Research gap on "investors' attention" are identified and filled by providing empirical evidence from the Nigerian stock market. To evaluate the impact of investors' online search intensity (using AGSV and AWiki) in explaining and predicting abnormal returns (ARet), trading volume and volatility, we employ the multivariate regression models. Results shown in Tables $2-4$ and Table A2, have small values of $R^{2}$ and adjusted $R^{2}$ but are with robust white heteroscedasticity-consistent (Eicker-White) standard errors.

Tables 2-4, columns (1)-(11) shows the coefficient estimations and the robust standard errors (in square bracket) of results from our analysis. The table displays results from both the descriptive and predictive model in univariate and multivariate form. The contemporaneous weekly abnormal stock returns are significantly positively correlated with its lag values due to the autoregressive nature of ARet time series, see Table 2. Although significant at $99 \%$ confidence level at the initial regression of the contemporaneous model, the AGSV becomes insignificant (both in univariate and multivariate models) when regressed together with other variables both in descriptive and predictive models. However, changes in the numbers of AWiki page view are highly significant and negatively explaining the variation in the stock returns (ARet). This implies that a higher stock return could lead to a smaller number of investors viewing wiki pages related to stock activities. This is likely the case of a worried investors who get very nervous about the stock market. Hence, they quickly seek information about the financial market before trying to dump their stock. This behavior increases stocks trading activities before crashes.

Results from Eqns (9) and $\left(9^{\prime}\right)$ shown in Table A1, investigate the impact of search queries with the abnormal trading volume (ATVol) as the dependent variable. Similarly, the AGSV can neither explain nor predict the ATVol of firms listed on NGSE-30 index, as demonstrated in both the univariate and multivariate models. The AWiki page view is positively insignificant in predicting the (ATVol) both in the univariate and multivariate models, see; Columns (8) and (11). However, it is significant at 99\% confidence level in the descriptive model when the explanatory multivariate model in column (6) is applied. Results also indicate that with $99 \%$ confidence level, most of the variation in ATVol can be explained by the variable (ATVol) using the current and previous weeks. Although the
The Nigerian stock market activities

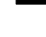


JED

23,1

68
Table 2.

Regression results from descriptive and predictive models of ARET, regress on AGSV, AWiki and other control variables. Columns (1)-(6) report results from a single regression models to explain the various independent variables. Columns (6) corresponds to multiple explanatory regressions model. Columns (7)-(11) display the corresponding results for predictive models

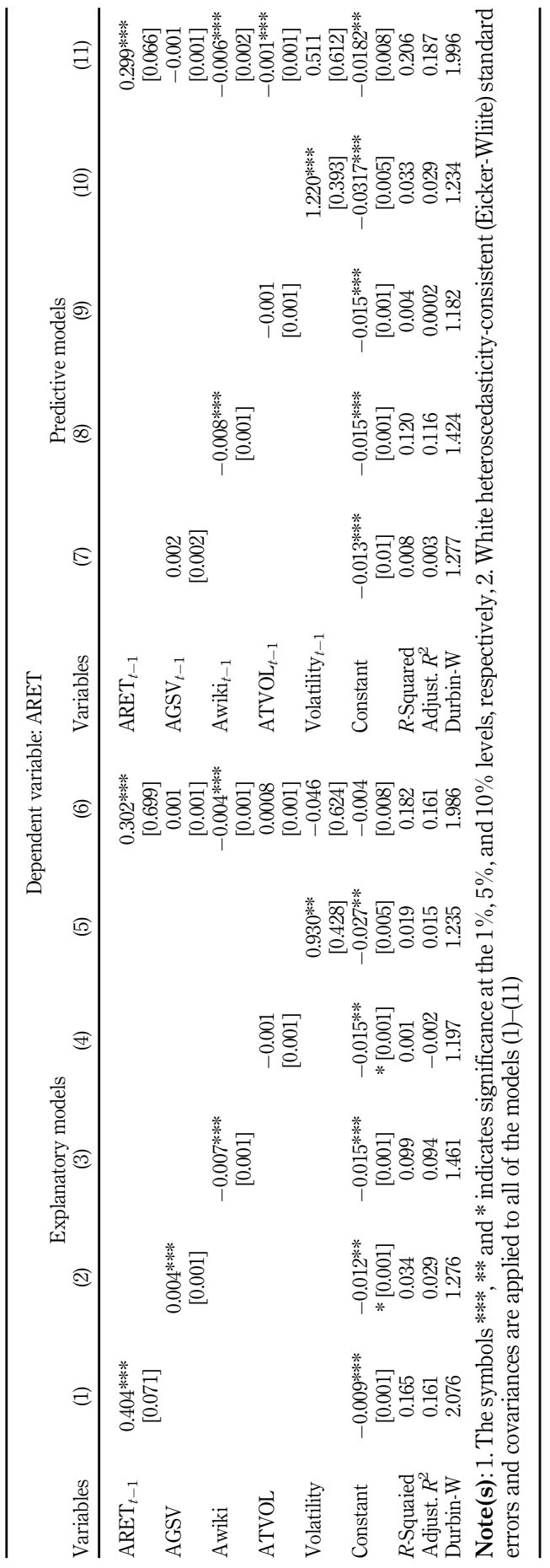




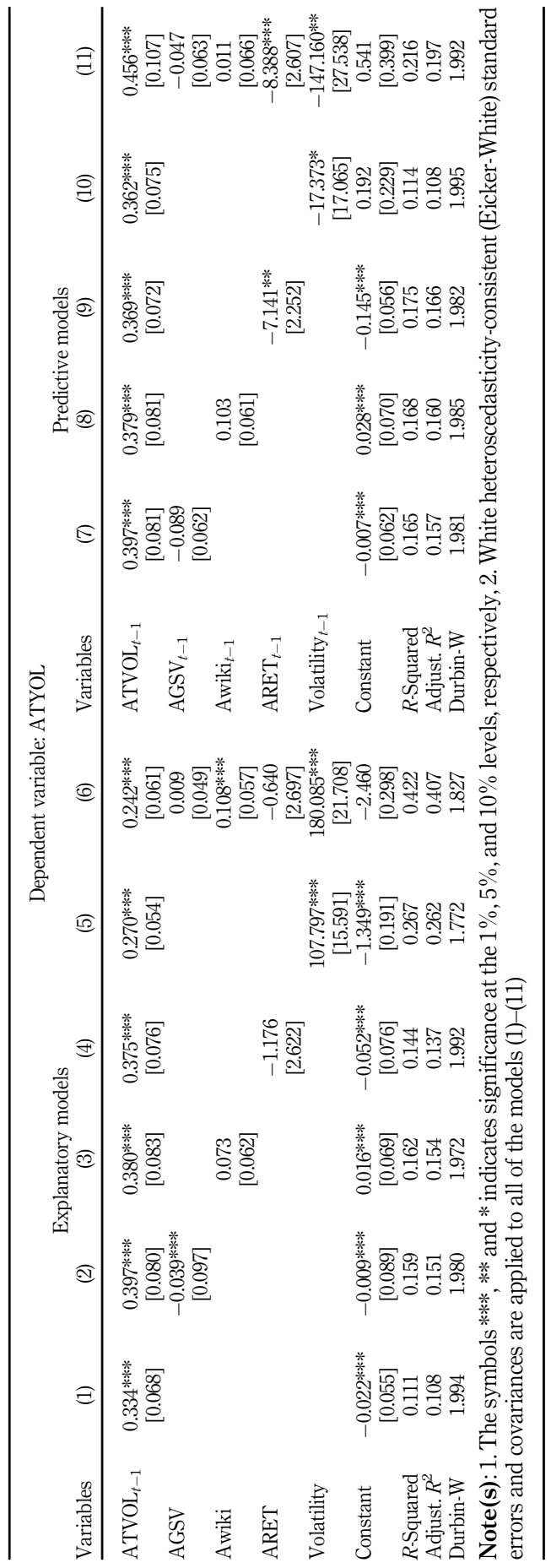

The Nigerian stock market activities

Table 3.

Regression results from descriptive and predictive models of ATVOL, regress on AGSV, Awiki and other control variables. Columns (1)-(6) report results from a single regression models to explain the various independent variables. Columns (6) corresponds to multiple explanatory regressions model.

Columns (7)-(11) display the corresponding results for predictive models 
JED

23,1

70

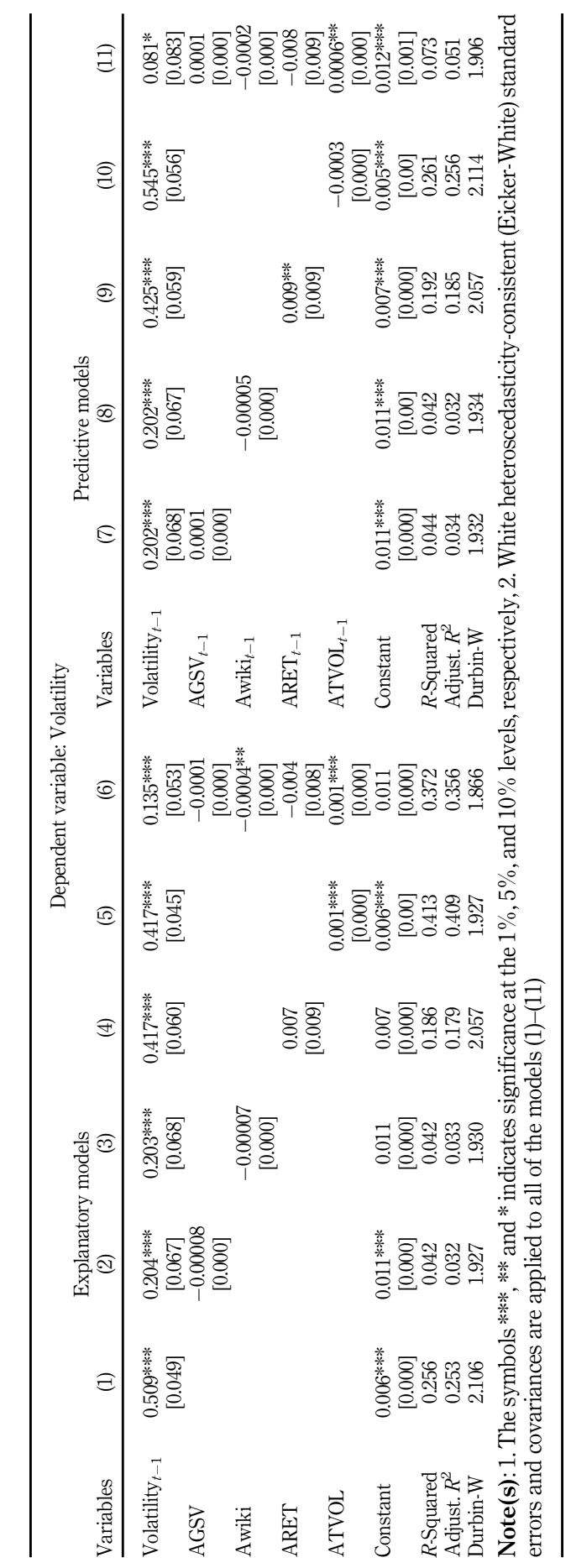

Table 4.

Regression results from descriptive and predictive models of Volatility, regressed on AGSV, AWiki and other control variables. Columns (1)-(6) report results from a single regression models to explain the various independent variables. Columns (6) corresponds to multiple explanatory regressions model. Columns (7)-(11) display the corresponding results for predictive model 
regression values of $R$ squared and adjusted $R^{2}$ are small, the values of the Durbin Watson test statistic indicates that variables are serial correlation free and the estimated coefficients results are Eicker-White robust. Finally, the estimation in Eqns (10) and (10') shown in Table 4 reveals the drivers of movements in the volatility dynamics of NGSE-30 index. The estimated values of $A G S V$ in the two models (explanatory and predictive), with Volatility as the dependent variable are insignificant. This suggests that AGSV does not influence volatility dynamics of firms on NGSE-30 index. Nevertheless, changes in AWiki page views negatively explain volatility, (see; column (6)) when other variables are taken into consideration.

\subsection{Robustness check}

In this section, we examine the adequacy of our models by performing robustness check. We used five lags predictive model to compare our main results in Tables 2-4. We apply the Bijl et al. (2016) standardization in our main model and Da et al. (2011) standardization for the new model. The models result from both standardizations are compared. Results from both models are expected to be the same.

For the alternative model, we used the detrended volume, AGSV and AWiki standardization by Da et al. (2011), excess stock return and volatility. The stock return, volume and volatility are also controlled in the predictive model of five lags for each variable, see Appendix 1, Eqn (11)-(14). We denote the five most recent lags as; $\sum_{i=1}^{5} L^{i}$, where $L^{i}$ is the lag operator. The multiple regression with robust white heteroscedasticity-consistent (EickerWhite) standard errors is the model estimation with results for the two methods shown in Appendix 1, Table A2. We regress ARet on AGSV and AWiki including the control variables. Our results indicate the following; The lag values and directions of AWiki in lags 1, 2, 3, 4 and 5 have weak negative coefficients. For AGSV, the directions and coefficients in lags 1, 2 and 5 are similar and very weak for both SM (A) and (B). AGSV lag 1 for SM (A) is significant, but non-significant in SM (B). We also observed an increase in $R$ squared and adjusted $R$ squared for both SM, coupled with a better Durbin-Watson test statistic. This result is similar to our main results in Table 2, that the AGSV neither predict the stock returns while the AWiki predict returns negatively.

We also compare the results of trading volume for both SM (A) and (B), shown on Appendix 1, Table A2. The AGSV have weak coefficients with positive non-significant directions at lags 2, 3 and 5. Even so, the AWiki coefficients for both SM are in different directions and non-significant. These results imply that both the AGSV and AWiki does not predict the values of the trading volume. Lastly, the regression estimation results in Appendix 1, Table A2 also reports volatility results using the alternative model for both SM (A) and (B) in five lags. Except for AGSV lag 1, other lags (2,3,4 and 5) have coefficients with the same directions but weak non-significant values. Similarly, the lags values of AWiki in both SM are in different directions, non-significant and weak. This estimation result is similar to results in Table 4 in our main study. Above all, the estimation results on Tables $2-4$ are consistent with results from both SM (A) and (B) as shown in Appendix 1, Table A2. This implies that investors' Google searches does not predict the stock returns, trading volumes and the volatility dynamics of NGSE-30 index. We also obtained results similar in Tables $2-4$ for descriptive model for both SM (A) and (B), but for brevity, we choose to report results with the predictive model.

\section{Conclusion}

In this paper, we examined empirically whether investors' online search intensity measured by GSV and Wikipedia page views influences the stock return, trading volume and the
The Nigerian stock market activities 
JED

23,1

72

volatility dynamics of the Nigerian stock market. Our analysis covers the top thirty (30) firms in Nigeria stock market exchange with respect to their market capitalization and liquidity. Our analyzed empirical results suggest that the use of data information offered by Wikipedia and Google services can be of great benefit to active and prospective investors as well as individual companies. Results show that the GSV does not influence firms listed on NGSE-30 index. Nevertheless, changes in the numbers of Wikipedia page views related to stock market activities negatively impact both the contemporary explanatory and predictive stock returns. Negative significant influence of attention on stock returns implies that, higher investors attentiveness by viewing firm's Wikipedia pages related to stocks market might lead to lower stock returns. This suggest that investors of NGSE-30 index companies appear to be more sensitive to bad news than good news in their investment decision. In summary, this article suggests that Google query for searching stock related information is not a driving factor for price movement for companies in NGSE-30 and appears not to interact with return, trading volume and volatility when determining price dynamics.

\section{Notes}

1. Google search statistics (2019), https://99firms.com/blog/google-search-statistics

2. The World Bank in Africa (2019), https://www.worldbank.org/en/region/afr/overview

3. Africa Internet Users Statistics (2019), https:/www.internetworldstats.com/stats1.htm.

4. Nigerian Communications Commission (2019), https://www.ncc.gov.ng

\section{References}

Adachi, Y., Masuda, M. and Takeda, F. (2017), "Google search intensity and its relationship to the returns and liquidity of Japanese startup stocks", Pacific Basin Finance Journal, Vol. 46, pp. 243-257.

Alizadeh, S., Brandt, W.M. and Diebold, X.F. (2002), "Range-based estimation of stochastic volatility models", Journal of Finance, Vol. 57, pp. 1047-1091.

Antweiler, W. and Frank, M.Z. (2004), "Is all that talks just noise? The information content of internet stock message boards", The Journal of Finance, Vol. 59, pp. 1259-1294.

Aouadi, A., Arouri, M. and Teulon, F. (2013), "Investor attention and stock market activity: evidence from France", Economic Modelling, Vol. 35, pp. 674-681.

Audrino, F., Sigrist, F. and Ballinari, D. (2019), "The impact of sentiment and attention measures on stock market volatility", International Journal of Forecasting, doi: 10.1016/j.ijforecast.2019.05.010.

Bank, M., Larch, M. and Peter, G. (2011), "Google search volume and its influence on liquidity and returns of German stocks", Financial Markets and Portfolio Management, Vol. 253, pp. 239-264.

Batista, G. and Monard, M. (2003), "An analysis of four missing data treatment methods for supervised learning”, Applied Artificial Intelligence, Vol. 17 No. 5-6, pp. 519-533.

Bijl, L., Kringhaug, G., Molnár, P. and Sandvik, E. (2016), “Google searches and stock returns”, International Review of Financial Analysis, Vol. 45, pp. 150-156.

Brandt, W.M. and Kinlay, J. (2005), Estimating Historical Volatility, available at: http://www. investment-analytics.com.

Cergol, B. and Omladič, M. (2015), "What can Wikipedia and Google tell us about stock prices under different market regimes?”, Ars Mathematica Contemporanea, Vol. 9 No. 2, pp. 301-320.

Chesney, M., Crameri, R. and Mancini, L. (2015), "Detecting abnormal trading activities in option markets", Journal of Empirical Finance, Vol. 33, pp. 263-275.

Chung, K.H. and Chuwonganant, C. (2018), "Market volatility and stock returns: the role of liquidity provider", Journal of Financial Markets, Vol. 37, pp. 17-34. 
Da, Z., Engelberg, J. and Gao, P. (2011), "In search of attention", The Journal of Finance, Vol. 66 No. 5, pp. 1461-1499.

Dimpfl, T. and Jank, S. (2016), "Can internet search queries help to predict stock market volatility?", European Financial Management, Vol. 22 No. 2, pp. 171-192.

Dimpfl, T. and Kleiman, V. (2019), "Investor pessimism and the German stock market: exploring google search queries", German Economic Review, Vol. 20 No. 1, pp. 1-28.

Fama, E.F. and French, K.R. (1993), "Common risk factors in the returns on stocks and bonds", Journal of Financial Economics, Vol. 33 No. 1, pp. 3-56.

Fama, E.F. and French, K.R. (2015), "A five-factor asset pricing model", Journal of Financial Economics, Vol. 116 No. 1, pp. 1-22.

Fang, L. and Peress, J. (2009), "Media coverage and the cross-section of stock returns", The Journal of Finance, Vol. 645, pp. 2023-2052.

Fehle, F., Tsyplakov, S. and Zdorovtsov, V. (2005), "Can companies influence investor behavior through advertising? super bowl commercials and stock returns", European Financial Management, Vol. 11, pp. 625-647.

Garman, M.B. and Klass, M.J. (1980), "On the estimation of security price volatilities from historical data", Journal of Business, Vol. 53 No. 1, pp. 67-78.

Hervé, F., Zouaoui, M. and Belvaux, B. (2019), "Noise traders and smart money: evidence from online searches", Economic Modelling, Vol. 83, pp. 141-149.

Huang, M.Y., Rojas, R.R. and Convery, P.D. (2019), "Forecasting stock market movements using google trend searches", Empirical Economics, doi: 10.1007/s00181-019-01725-1.

Kim, Y.H. and Meschke, F. (2011), "CEO interviews on CNBC", Working Paper, available at: http:// ssrn.com/abstract $=1745085$.

Kim, N., Lucivjanska, K., Molnar, P. and Villa, R. (2019), "Google searches and stock market activities: evidence from Norway”, Finance Research Letters, Vol. 28, pp. 208-220.

Moat, H.S., Curme, C., Avakian, A., Kenett, D.Y., Stanley, H.E. and Preis, T. (2013), "Quantifying wikipedia usage patterns before stock market moves”, Scientific Reports, Vol. 3, pp. 1801, doi: 10.1038/srep01801.

Parkinson, M. (1980), "The extreme value method for estimating the variance of the rate of return", Journal of Business, Vol. 53, pp. 61-68.

Preis, T., Moat, H.S. and Stanley, H.E. (2013), "Quantifying trading behavior in financial markets using Google Trends", Scientific Reports, Vol. 3, pp. 1684.

Rogers, L.C.G. and Satchell, S.E. (1991), "Estimating variance from high, low and closing prices", Annals of Applied Probability, Vol. 1, pp. 504-512.

Takeda, F. and Wakao, T. (2014), "Google search intensity and its relationship with returns and trading volume of Japanese stocks", Pacific-Basin Finance Journal, Vol. 27, pp. 1-18.

Takeda, F. and Yamazaki, H. (2006), "Stock price reactions to public TV programs on listed Japanese companies", Economics Bulletin, Vol. 137, pp. 1-7.

Yang, D. and Zhang, Q. (2000), "Drift independent volatility estimation based on high, low, open and close prices”, Journal of Business, Vol. 73, pp. 477-491.

Yoshida, M., Arase, Y., Tsunoda, T. and Yamamoto, M. (2015), "Wikipedia page view reflects web search trend", Proceedings of the 2015 ACM Web Science Conference, November, California, CA, Article No. 65, pp. 1-2, doi: 10.1145/2786451.2786495.

Zagoruyko, S. and Komodakis, N. (2019), "Paying more attention to attention: improving the performance of convolutional neural networks via attention transfer", 5th International Conference on Learning Representations, Iclr 2017 - Conference Track Proceedings, New Orleans, Louisiana.

Zhang, J., Djajadikerta, H.G. and Zhang, Z. (2018), "Does sustainability engagement affect stock return volatility? Evidence from the Chinese financial market”, Sustainability, Vol. 10 No. 10, pp. 336. 
JED

23,1

74

\section{Further reading}

Joseph, K., Wintoki, M.B. and Zhang, Z. (2011), "Forecasting abnormal stock returns and trading volume using investor sentiment: evidence from online search", International Journal of Forecasting, Vol. 27 No. 4, pp. 1116-1127.

Khelladi, I. and Boutinot, A. (2017), "The role of wikipedia on corporate E-reputation: evidence from French companies", International Studies of Management and Organization, Vol. 47 No. 1, pp. 23-41.

\section{Appendix 1}

$$
\begin{aligned}
& \operatorname{AGSV}_{t}^{d}=\operatorname{logGSV}{ }_{t}-\log \left[\operatorname{Median}\left(\mathrm{GSV}_{t-1}, \ldots, \mathrm{GSV}_{t-52}\right)\right] \\
R_{t}= & \alpha+\left(\sum_{i=1}^{5} \beta_{t} L^{i}\right) R_{t}+\left(\sum_{i=1}^{5} \gamma_{t} L^{i}\right) \mathrm{GSV}_{t}+\left(\sum_{i=1}^{5} \delta_{t} L^{i}\right) \mathrm{Wiki}_{t} \\
& +\left(\sum_{i=1}^{5} \zeta_{t} L^{i}\right) \text { Volume }_{t}+\left(\sum_{i=1}^{5} \eta_{t} L^{i}\right) \text { Volatility }_{t}+\varepsilon_{t} \\
\text { Volume }_{t}=\alpha & +\left(\sum_{i=1}^{5} \beta_{t} L^{i}\right) \text { Volume }_{t}+\left(\sum_{i=1}^{5} \gamma_{t} L^{i}\right) \mathrm{GSV}_{t}+\left(\sum_{i=1}^{5} \delta_{t} L^{i}\right) \mathrm{Wiki}_{t} \\
& +\left(\sum_{i=1}^{5} \zeta_{t} L^{i}\right) \operatorname{Return}_{t}+\left(\sum_{i=1}^{5} \eta_{t} L^{i}\right) \operatorname{Volatility}_{t}+\varepsilon_{t} \\
\text { Volatility }_{t}= & \alpha+\left(\sum_{i=1}^{5} \beta_{t} L^{i}\right) \operatorname{Volatility}_{t}+\left(\sum_{i=1}^{5} \gamma_{t} L^{i}\right) \mathrm{GSV}_{t}+\left(\sum_{i=1}^{5} \delta_{t} L^{i}\right) \text { Wiki }_{t} \\
& +\left(\sum_{i=1}^{5} \zeta_{t} L^{i}\right) \operatorname{Return}_{t}+\left(\sum_{i=1}^{5} \eta_{t} L^{i}\right) \operatorname{Volume}_{t}+\varepsilon_{t}
\end{aligned}
$$

where; $L$, denote the lag operator and $\sum_{i=1}^{5} L^{i}$ indicates a lag operator with five most recent lags. 


\begin{tabular}{|c|c|c|c|c|}
\hline $\mathrm{S} / \mathrm{N}$ & Ticker & Company & Sector & \multirow{3}{*}{$\begin{array}{r}\text { The Nigerian } \\
\text { stock market } \\
\text { activities }\end{array}$} \\
\hline \multicolumn{4}{|l|}{ Panel A } & \\
\hline 1 & Access & Access bank PLC. & Financial services & \\
\hline 2 & ConoiL & Conoil PLC & Oil and gas & \\
\hline 3 & Dangcem & Dangote cement PLC & Industrial goods & \\
\hline 4 & FBNH & FBN holdings PLC & Financial services & \\
\hline 5 & Flourmill & Flour mills Nig. PLC. & Consumer goods & 75 \\
\hline 6 & FO & Forte oil PLC. & Oil and gas & \\
\hline 7 & Guaranty & Guaranty trust bank PLC. & Financial services & \\
\hline 8 & Guinness & Guinness NIG PLC & Consumer goods & \\
\hline 9 & Intbrew & International breweries PLC. & Consumer goods & \\
\hline 10 & Jberger & Julius berger NIG. PLC. & Construction/real est. & \\
\hline 11 & Wapco & Lafarge Africa PLC. & Industrial goodS & \\
\hline 12 & Nestle & Nestle Nigeria PLC. & Consumer goods & \\
\hline 13 & NB & Nigerian brew. PLC. & Consumer goods & \\
\hline 14 & Oando & Oando PLC & Oil and gas & \\
\hline 15 & $\mathrm{PZ}$ & P Z Cussons Nigeria PLC. & Consumer goods & \\
\hline 16 & Seplat & Seplat petrol. dev. comp. PLC & Oil and gas & \\
\hline 17 & Stanbic & Stanbic IBTC holdings PLC & Financial services & \\
\hline 18 & Sterlnbank & Sterling bank PLC. & Financial services & \\
\hline 19 & Transcorp & Transnational corp. of Nig. PLC & Conglomerates & \\
\hline 20 & UACN & U A C N PLC. & Conglomerates & \\
\hline 21 & UBA & United bank for Africa PLC & Financial services & \\
\hline 22 & Unitybnk & Unity bank PLC & Financial services & Table A1. \\
\hline 23 & Unilever & Unilever Nigeria PLC. & Consumer goods & Twenty-four (24) \\
\hline 24 & Zenithbank & Zenith bank PLC & Financial services & NGSE-30 stock \\
\hline Panel B & & & & companies index with \\
\hline & Mobil & 11 PLC & Conglomerates & $\begin{array}{l}\text { tickers as well as their } \\
\text { associated sector }\end{array}$ \\
\hline 2 & Dangsugar & DANGOTE SUGAR REFINERY PLC & Consumer goods & included in our sample \\
\hline 3 & ETI & ECOBANK TRANSNATIONAL INCORP. & Financial services & for empirical analysis. \\
\hline 4 & Okomuoil & OKOMU OIL PALM PLC. & Agriculture & This reduction is due to \\
\hline 5 & Presco & PRESCO PLC & Agriculture & non-availability of \\
\hline 6 & Total & Total Nigeria PLC. & Oil and gas & stock data \\
\hline
\end{tabular}

\begin{tabular}{|c|c|c|c|c|c|c|c|}
\hline \multirow[b]{2}{*}{ Variables } & \multicolumn{2}{|c|}{ Returns } & \multicolumn{2}{|c|}{ Trading volume } & \multicolumn{2}{|c|}{ Volatility } & \\
\hline & SM: A & SM: B & SM: A & SM: B & SM: A & SM: B & \\
\hline Constant & $-0.0420^{* * * *}$ & $-0.0447 * * *$ & 0.184 & -0.191 & $0.008 * * *$ & $0.009 * * *$ & \\
\hline Return $_{t-1}$ & $0.2989 * *$ & $0.3136^{* * * *}$ & $-7.575^{* * * *}$ & $-1.864^{* *}$ & -0.015 & -0.011 & \\
\hline $\operatorname{Return}_{t-2}$ & 0.0063 & -0.0499 & -0.344 & -0.500 & 0.008 & 0.004 & \\
\hline $\operatorname{Return}_{t-3}$ & -0.0382 & 0.0422 & -1.230 & 0.102 & 0.0002 & 0.002 & \\
\hline $\operatorname{Return}_{t-4}$ & -0.023 & -0.0257 & 1.284 & 0.613 & -0.006 & -0.003 & \\
\hline Return $_{t-5}$ & 0.0477 & 0.0633 & -3.908 & -0.536 & 0.003 & 0.011 & \\
\hline Volume $_{t-1}$ & -0.0009 & -0.0012 & $0.411 * * *$ & $0.367 * * *$ & $0.0005^{*}$ & $0.001 *$ & \\
\hline Volume $_{t-2}$ & -0.0023 & -0.0016 & $0.003^{*}$ & $-0.134 * *$ & -0.0002 & 0.0001 & \\
\hline Volume $_{t-3}$ & 0.0003 & -0.00009 & -0.097 & 0.114 & -0.0003 & 0.0009 & \\
\hline Volume $_{t-4}$ & -0.0022 & -0.0018 & $0.123^{*}$ & $0.100^{*}$ & $0.0002^{*}$ & $0.001^{*}$ & Table A2 \\
\hline Volume $_{t-5}$ & 0.0015 & 0.00002 & $0.160 *$ & $-0.139 *$ & 0.0002 & -0.0008 & model robustness SM \\
\hline Volatility $_{t-1}$ & 0.2164 & 0.6844 & -30.264 & -10.683 & $0.143 *$ & $0.159 * *$ & $(\mathrm{~A})$ and $(\mathrm{B})$ indicates \\
\hline Volatility $_{t-2}$ & 0.5015 & 0.1020 & $18.491^{*}$ & $-5.654 * *$ & 0.0278 & -0.045 & $\begin{array}{l}\text { (11) } \\
\text { standardization }\end{array}$ \\
\hline Volatility $_{t-3}$ & 1.4482 & $1.4942^{* *}$ & $73.890 * * * *$ & $24.375^{*}$ & $0.328 * * *$ & $0.225^{* * * *}$ & methods by Bijl et al \\
\hline & & & & & & (continued) & $\begin{array}{l}\text { (2016) and Da et al } \\
\text { (2011) respectively }\end{array}$ \\
\hline
\end{tabular}




\begin{tabular}{lcccccc}
\hline & \multicolumn{2}{c}{ Returns } & \multicolumn{2}{c}{ Trading volume } & \multicolumn{2}{c}{ Volatility } \\
Variables & SM: A & SM: B & SM: A & SM: B & SM: A & SM: B \\
\hline Volatility $_{t-4}$ & -0.2415 & -0.2485 & -16.792 & -0.796 & $0.176^{* *}$ & $0.183^{* * *}$ \\
Volatility $_{t-5}$ & 0.2558 & 0.5972 & $-73.140^{* *}$ & $1.712^{*}$ & $-0.291^{*}$ & $-0.208^{* *}$ \\
Wiki $_{t-1}$ & $0.0003^{*}$ & 0.0037 & -0.154 & $0.568^{* *}$ & -0.0002 & 0.004 \\
Wiki $_{t-2}$ & $-0.0082^{* * *}$ & $-0.043^{*}$ & 0.299 & $-0.602^{*}$ & 0.0001 & 0.001 \\
Wiki $_{t-3}$ & $0.0064^{* *}$ & $0.0094^{*}$ & -0.248 & 0.199 & -0.00009 & 0.0004 \\
Wiki i $_{t-4}$ & -0.0007 & -0.0218 & -0.111 & 0.337 & -0.0002 & -0.003 \\
Wiki $_{t-5}$ & $-0.0048^{* *}$ & $-0.0042^{*}$ & 0.118 & -0.175 & 0.0001 & -0.002 \\
GSVI $_{t-1}$ & $-0.0045^{*}$ & -0.0154 & -0.058 & 0.145 & 0.00030 & -0.00008 \\
GSVI $_{t-2}$ & 0.0044 & $0.0367^{*}$ & 0.088 & 0.217 & 0.0001 & 0.002 \\
GSVI $_{t-3}$ & 0.00006 & -0.0362 & 0.020 & 0.089 & 0.00001 & 0.00009 \\
GSVI $_{t-3}$ & -0.0009 & 0.0522 & -0.141 & 0.105 & $-0.005^{* *}$ & -0.001 \\
GSVI $_{t-5}$ & -0.0003 & -0.0343 & 0.006 & 0.079 & 0.00004 & 0.0002 \\
$R$ Squared $^{*}$ & 0.303 & 0.3122 & 0.345 & 0.340 & 0.320 & 0.317 \\
Adjusted $^{2}$ & 0.206 & 0.2161 & 0.253 & 0.248 & 0.225 & 0.221 \\
Durbin-Watson $^{*}$ & 2.003 & 2.0003 & 2.038 & 1.998 & 2.004 & 1.996
\end{tabular}

Note(s): Robust standard errors are reported in square bracket and significant level

Table A2.

$* p$-value $<0.1 ; * * p$-value $<0.05 ; * * * p$-value $<0.01$

\section{Corresponding author}

Osarumwense Osabuohien-Irabor can be contacted at: oosabuokhien-irabor@urfu.ru

For instructions on how to order reprints of this article, please visit our website:

www.emeraldgrouppublishing.com/licensing/reprints.htm

Or contact us for further details: permissions@emeraldinsight.com 